\title{
Correction to: Personality Traits and Individual Attitudes Toward Same-Sex-Marriage: Evidence from Taiwan
}

\section{Ching-Hsing Wang ${ }^{1} \cdot$ Tsong-Jyi Lin $^{2} \cdot$ Dennis Lu-Chung Weng ${ }^{3} \cdot$ Yi-Bin Chang ${ }^{2}$}

Published online: 4 December 2019

(C) Springer Science+Business Media, LLC, part of Springer Nature 2019

\section{Erratum to: Sexuality Research and Social Policy} https://doi.org/10.1007/s13178-019-00401-4

The original version of this article unfortunately contained a mistake.

- The name of "Tsong-Jyi Lin" is now corrected in the author group of this article.

- The correct image for Fig. 2 is presented here.

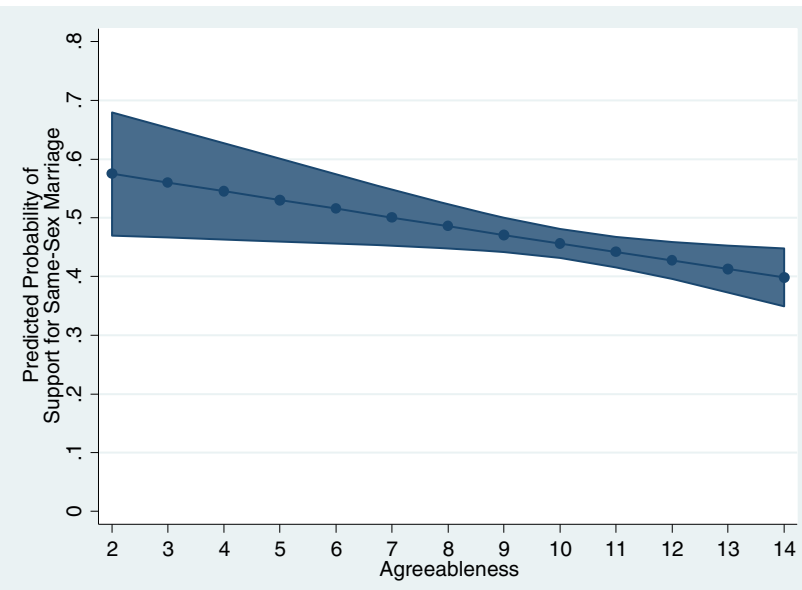

The online version of the original article can be found at https://doi.org/ 10.1007/s13178-019-00401-4

Ching-Hsing Wang

chinghsing.wang@gmail.com

Tsong-Jyi Lin

tjlin@mail.tku.edu.tw

Dennis Lu-Chung Weng

dennis.weng@shsu.edu

Yi-Bin Chang

cyb@mail.tku.edu.tw

1 Department of Political Science, National Cheng Kung University, No. 1, University Road, Tainan City 701, Taiwan, Republic of China

2 Department of Public Administration, Tamkang University, No.

151,Yingzhuan Rd., Tamsui Dist., New Taipei City 25137, Taiwan, Republic of China

3 Department of Political Science, Sam Houston State University, SHSU Box 2149, Huntsville, TX 77341, USA 